\title{
LA REGULACIÓN DE LA JUSTICIA EN EL ESTATUTO DE AUTONOMÍA DE CATALUÑA: ESPECIAL REFERENCIA A LA SENTENCIA DEL TRIBUNAL CONSTITUCIONAL ESPAÑOL 31/2010, DE 28 DE JUNIO*
}

\author{
Regulation of Justice in the Statute of Autonomy of Catalonia: Special \\ reference to Judgment Spanish Constitutional Court 31/2010, of 28 june
}

Alejandro Villanueva Turnes ${ }^{* *}$

\begin{abstract}
Resumen: El presente trabajo tiene como finalidad analizar la parte del Estatuto de Autonomía de Cataluña relativa al Poder Judicial. Para lograr este objetivo se analizarán los distintos preceptos que tratan este tema así como la jurisprudencia que exista sobre los mismos. Hay que tener en cuenta que el enjuiciamiento del Estatuto de Autonomía de Cataluña por parte del Tribunal Constitucional es considerado por muchos autores como el desencadenante de la actual situación que se vive con la Comunidad Autónoma. Todo ello implica que el análisis de esta parte de la norma estatutaria, que ha sido una de las que más polémicas ha suscitado, se convierte en algo realmente interesante hoy en día.
\end{abstract}

Palabras Clave: Estatuto de Autonomía de Cataluña - sentencia del Tribunal Constitucional 31/2010 - bloque de la constitucionalidad - sentencia interpretativa Poder Judicial.

\begin{abstract}
This work has the objective of analysing of part of Statute of Autonomy of Catalonia relating to the Judicial Authority. To reach this objective will be analysed the different precepts and the jurisprudence that exist about them. It should be noted that the prosecution of Statute of Autonomy of Catalonia by the Constitutional Court Is considered by many such as trigger of the present situation in this Autonomous Community. All this implies that the analysis on this part of the Statute of Autonomy is a one thing really interesting today.
\end{abstract}

Keywords: Statute of Autonomy of Catalonia - Constitutional Court ruling 31/2010 block of constitutionality - interpretative ruling - Judicial Authority.

\section{Introducción}

En el año 2005 se aprueba en el Parlamento de Cataluña el texto de la Propuesta de Reforma del Estatuto de Autonomía de esta Comunidad Autónoma, el cual se

\footnotetext{
* El presente estudio se hizo en el marco del Máster Universitario de Derecho de las Administraciones e Instituciones Públicas de la Universidad de Santiago de Compostela.

** Doctorando en Derecho. Universidad de Santiago de Compostela. Correo electrónico: alejandro.villanueva@usc.es
}

Este artículo fue recibido el 21 de enero de 2016, siendo aprobada su publicación el 25 de mayo de 2016. 
remite a las Cortes Generales para su tramitación. Las numerosas contradicciones con la Lay Fundamental que contenía este texto, llevaron a las Cortes Generales a realizar una intensa revisión que afectó a 150 artículos de los 227 que lo componían. El texto es finalmente aprobado por el Congreso de Diputados con la introducción de las oportunas modificaciones y asimismo es aprobado por el Senado sin introducir modificación alguna. El 18 de junio de 2006 se somete el texto a referéndum que permite su aprobación definitiva. ${ }^{1}$ Finalmente, el 19 de julio del mismo año se sanciona y se promulga la Ley Orgánica de Reforma del Estatuto de Autonomía de Cataluña, publicándose en el Boletín Oficial del Estado al día siguiente.

A pesar de las numerosas modificaciones que se realizaron por parte del Congreso, no se logró adecuar plenamente el texto que tendría el nuevo Estatuto con el texto Constitucional. Esta inadecuación se pone de manifiesto no solo en lo relativo a que distintos profesionales del derecho así lo manifestasen, sino que también puede observarse en la presentación de nada más y nada menos que siete recursos de inconstitucionalidad, los cuales son:

1) Recurso 8045-2006, presentado por noventa y nueve diputados del partido popular el 31 de julio de 2006.

2) Recurso 8675-2006, presentado por el Defensor del Pueblo el 19 de septiembre de 2006.

3) Recurso 9330-2006, presentado por el Consejo de Gobierno de la Comunidad Autónoma de la Rioja el día 11 de octubre de 2006.

4) Recurso 9491-2006, presentado por la Diputación General de Aragón el 19 de octubre de 2006.

5) Recurso 9501-2006, presentado por la Generalitat de la Comunidad Valenciana el 19 de octubre de 2006.

6) Recurso 8829-2006, presentado por el gobierno de la Comunidad Autónoma de Murcia el 20 de octubre de 2006.

7) Recurso 9568-2006, presentado por la Comunidad Autónoma de las Islas Baleares el 20 de octubre de 2006.

De la resolución de estos siete recursos nacieron siete sentencias del Tribunal Constitucional en las cuales se vieron afectados un gran número de preceptos. De todas ellas, la principal y la más larga, es la que resuelve el primero de los recursos, que no es otra que la sentencia del Tribunal Constitucional (en adelante STC) 31/2010. ${ }^{2}$ Será esta sentencia la columna vertebral sobre la que se asiente este trabajo. Además, las sentencias que resuelven los restantes recursos no hacen otra

\footnotetext{
1 Hay que tener en cuenta que en dicho referéndum hay un alto porcentaje de abstención, porcentaje que se sitúa en el 50\%.

2 Tribunal Constitucional de España, 99 Diputados del Grupo Parlamentario Popular del Congreso (2010): 28 de junio de 2010 (Función y contenido constitucional del Estatuto de Autonomía de Cataluña - Recurso de inconstitucionalidad). Rol N $N^{\circ} 31 / 2010$, en página electrónica del Tribunal Constitucional http://hj.tribunalconstitucional.es/HJ/es/Resolucion/Show/6670.
} 
Villanueva - La regulación de la justicia ...

cosa que continuar el camino marcado por esta primera. Por ello, en lo que sigue, salvo que se manifieste lo contrario, será esta la sentencia que se estará examinando.

Hay que tener en cuenta que dentro de estas sentencias se pueden distinguir siete grandes bloques temáticos:

$\begin{array}{ll}- & \text { Derechos y Libertades } \\ - & \text { Nación } \\ - & \text { Lengua } \\ - & \text { Justicia } \\ - & \text { Blindaje Competencial } \\ - & \text { Financiación } \\ - & \text { Bilateralidad }\end{array}$

El presente estudio se va a centrar en el cuarto de los bloques que acaban de nombrarse, es decir, el bloque de Justicia. Lo que se hará es exponer uno a uno los preceptos que contiene el Estatuto de Autonomía, para posteriormente señalar la jurisprudencia que ha establecido el Tribunal Constitucional analizándola de forma crítica. Todo ello irá precedido de unas consideraciones previas aplicables a todas las sentencias en general y a este bloque temático en particular.

Antes de proseguir, es necesario comentar que los preceptos relativos al tema de la Justicia, son tratados casi en su totalidad en el primero de los recursos a los que se ha hecho mención, por lo que, con alguna excepción puntual, será en la sentencia 31/2010, en la que encontremos la solución dada por el Tribunal.

\section{Consideraciones previas: una referencia general a la noción de bloque de constitucionalidad y el alcance de las sentencias interpretativas}

La sentencia del Tribunal Constitucional $31 / 2010^{3}$ no solo es una de las sentencias más polémicas y más criticadas desde que el Tribunal Constitucional Español comenzó su labor, sino que además es una de las sentencias más importantes dentro de la jurisprudencia constitucional española desde la entrada en vigor de la Constitución de $1978 .{ }^{4}$ El tiempo que se tomó para resolver acerca del primer

\footnotetext{
3 Tribunal Constitucional de España, 99 Diputados del Grupo Parlamentario Popular del Congreso (2010): 28 de junio de 2010 (Función y contenido constitucional del Estatuto de Autonomía de Cataluña - Recurso de inconstitucionalidad). Rol N N 31/2010, en página electrónica del Tribunal Constitucional http://hj.tribunalconstitucional.es/HJ/es/Resolucion/Show/6670.

${ }^{4} \mathrm{La}$ importancia de esta sentencia es reconocida por todos los juristas españoles, situándola por encima de la de sentencias muy polémicas como son las del caso Rumassa o la sentencia sobre la doctrina Parot. Un sector importante de la doctrina considera que junto con la sentencia referida a la Ley Orgánica de Armonización del Proceso Autonómico, STC 76/1983 (Tribunal Constitucional de España, Gobierno Vasco, por el Parlamento Vasco, por el Consejo Ejecutivo de la Generalidad de Cataluña, por el Parlamento de Cataluña y por 50 Diputados de las Cortes Generales (1983): 5
} 
recurso de inconstitucionalidad interpuesto sobre el Estatuto de Autonomía de Cataluña, nada más y nada menos que cerca de cuatro años, era una señal inequívoca de que el resultado iba a ser cuanto menos, sorprendente, y en verdad así fue, ya que la mencionada sentencia no ha dejado indiferente a nadie. ${ }^{5}$

Esta sentencia 31/2010, ${ }^{6}$ se dicta, tal y como señala Albertí Rovira, “en un contexto extraordinariamente conflictivo, en medio de un enorme debate político y jurídico, en ocasiones muy tenso, en cuyo centro se encontraba el nuevo Estatuto de Cataluña y las novedades que representaba respecto del Estado autonómico tal como se había configurado hasta el momento". " Este contexto se manifiesta, primero, en la impugnación de esta reforma del Estatuto de Autonomía de Cataluña cuando otros Estatutos con preceptos similares no han sido impugnados, y en segundo lugar, en el tema relativo a la composición del Tribunal Constitucional.

La explicación de esta primera manifestación relativa a la impugnación del Estatuto de Cataluña pero no de otros similares se debe, tal y como se ha señalado en alguna ocasión, a que estos otros Estatutos con preceptos similares no pertenecían a Comunidades Autónomas conflictivas con el Estado propiamente dicho.

En cuanto a su composición, los miembros del Tribunal fueron calificados por la prensa de progresistas y conservadores, calificaciones propias del derecho estadounidense, y cada miembro fue sometido a un examen intenso para solicitar las recusaciones oportunas. Respecto de esto, solo el magistrado don Pablo Pérez Tremps fue recusado, por aceptación del propio Tribunal, al haber participado en un informe sobre la constitucionalidad del Estatuto catalán, recusación que no se aceptó sobre la presidenta del Tribunal, doña Emilia Casas. ${ }^{8}$ Sumado a esto, otros aspectos que hacen ver este difícil contexto al que se ha hecho referencia, es la

de agosto de 1983 (Proyecto de Ley Orgánica Armonizadora del Proceso autonómico - Recurso de inconstitucionalidad). Rol $\mathrm{N}^{\circ} 76 / 1983$, en página electrónica del Tribunal Constitucional http://hj.tribunalconstitucional.es/HJ/es/Resolucion/Show/204), la STC 31/2010 es la más importante (Tribunal Constitucional de España, 99 Diputados del Grupo Parlamentario Popular del Congreso (2010): 28 de junio de 2010 (Función y contenido constitucional del Estatuto de Autonomía de Cataluña - Recurso de inconstitucionalidad). Rol N ${ }^{\circ} 31 / 2010$, en página electrónica del Tribunal Constitucional http://hj.tribunalconstitucional.es/HJ/es/Resolucion/Show/6670.

5 Prueba de ello son las numerosas menciones con las que cuenta en los periódicos españoles más destacados, los estudios realizados sobre el tema y los comentarios de juristas y políticos que se han realizado al respecto.

6 Tribunal Constitucional de España, 99 Diputados del Grupo Parlamentario Popular del Congreso (2010): 28 de junio de 2010 (Función y contenido constitucional del Estatuto de Autonomía de Cataluña - Recurso de inconstitucionalidad). Rol No 31/2010, en página electrónica del Tribunal Constitucional http://hj.tribunalconstitucional.es/HJ/es/Resolucion/Show/6670.

${ }^{7}$ Albertí Rovira (2010), p. 12.

${ }^{8}$ Esta denegación fue duramente criticada ya que el cónyuge de Casas, con el que la presidenta tenía un régimen de gananciales, había participado en el mismo informe que don Pablo Pérez Tremps. 
Villanueva - La regulación de la justicia ...

prolongación en el mandato de los magistrados y el fallecimiento de uno de ellos, situando en 10 el número que conformaría el pleno para resolver sobre el tema.

Un asunto de suma importancia que estuvo en el punto de mira desde la presentación de los recursos de inconstitucionalidad fue el relativo a la competencia del Alto Tribunal para conocer de estos recursos. Como es evidente, el Tribunal se consideró competente, prueba de lo cual están las distintas sentencias dictadas sobre el Estatuto, pero, desde un punto de vista personal del autor de este trabajo, no hay ningún tipo de duda al respecto ya que el propio artículo 27.2.a de la Ley Orgánica del Tribunal Constitucional, establece la posibilidad de que los Estatutos de Autonomía sean susceptibles de declaración de inconstitucionalidad. Ahora bien, se ha considerado que al tratarse de un Estatuto aprobado por los ciudadanos de la Comunidad Autónoma en referéndum, ello supondría una situación especial respecto a la establecida en este artículo, y por tanto un caso que podría cuestionar la competencia del Tribunal. Sin embargo, esto no es así, ya que desde un punto de vista estrictamente jurídico, los Estatutos son susceptibles de ser juzgados por el Alto Tribunal con indiferencia de si han sido sometidos a referéndum o no, dado que la Ley Orgánica del Tribunal Constitucional no establece ninguna diferenciación a este respecto.

En este sentido es necesario proseguir diciendo que la sentencia clave sobre la que versa este estudio supone un antes y un después dentro de la jurisprudencia constitucional del ordenamiento jurídico español. El motivo de esto es, en primer lugar, porque la STC $31 / 2010^{9}$ implica la fijación del Estatuto de Autonomía como norma inferior a la Constitución Española dentro del denominado bloque de la constitucionalidad. ${ }^{10}$

Hay que aclarar que el llamado bloque de la constitucionalidad es un término que nace en Francia a raíz de la sentencia del Consejo Constitucional de 16 de julio de 1971. Tal y como se establece en esta resolución, como la Constitución Francesa de 1958 hacía referencia, en su preámbulo, a la Constitución de 1946 y a la Declaración de Derechos del Hombre y del Ciudadano de 1789, estas normas y principios tenían que ser integradas a la Constitución, adquiriendo así valor constitucional y formando el llamado bloque de la constitucionalidad. Esto significaba que se trataba de normas que los jueces pueden aplicar de forma directa y que el legislador debe respetar, y al mismo tiempo deben ser utilizadas a la hora de resolver los juicios de constitucionalidad que se presenten.

\footnotetext{
9 Tribunal Constitucional de España, 99 Diputados del Grupo Parlamentario Popular del Congreso (2010): 28 de junio de 2010 (Función y contenido constitucional del Estatuto de Autonomía de Cataluña - Recurso de inconstitucionalidad). Rol No 31/2010, en página electrónica del Tribunal Constitucional http://hj.tribunalconstitucional.es/HJ/es/Resolucion/Show/6670.

${ }^{10}$ En relación al bloque de la constitucionalidad resulta interesante confrontar el siguiente trabajo en el que se expone con una mayor amplitud el concepto y significado en el ordenamiento jurídico español así como una perspectiva jurisprudencial y de derecho comparado: VILLANUEVA TURNES (2014), pp. 59-70.
} 
Teniendo esto presente, puede decirse que una definición válida del bloque de la constitucionalidad sería "aquel conjunto de normas jurídicas que, junto a la Constitución, deben ser tenidas en cuenta por el órgano al que está atribuido el control de constitucionalidad para determinar la conformidad o disconformidad de las normas susceptibles de declaración de inconstitucionalidad con la Constitución". ${ }^{11}$ Analizando esta definición, se llega a una conclusión básica en relación a la misma, y es que el órgano encargado de decidir si una norma es conforme a la Constitución tiene la obligación de emplear todas las normas que forman parte del bloque de la constitucionalidad para tomar su decisión.

En España, la doctrina del bloque de la constitucionalidad adquiere un matiz diferente, puesto que el Tribunal Constitucional la utiliza en algunas ocasiones para resolver casos puntuales, y en otras situaciones es utilizado este bloque para referirse a unas normas que se sitúan por encima de otras en la distribución de competencias dentro del Estado Autonómico ${ }^{12}$.

Por su parte, tal y como señala Arturo Hoyos, ${ }^{13}$ el profesor Rubio Llorente ha considerado que el bloque de la constitucionalidad en el ordenamiento jurídico español está formado, en primer lugar, por la Constitución Española de 1978 (en adelante CE), y en segundo lugar, por los Estatutos de Autonomía y otras normas que se refieren a las competencias entre el Estado y las Comunidades Autónomas, aunque el propio Rubio Llorente ha dicho que no existen elementos capaces de determinar exactamente el contenido de dicho bloque. ${ }^{14}$

Concretamente, en lo que se refiere al Tribunal Constitucional Español propiamente dicho, lo menciona por primera vez en su sentencia 10/1982, aunque como bien ha advertido Rubio Llorente, no aparece definido hasta la sentencia 29/1982 como "un conjunto de normas que ni están incluidas en la Constitución ni delimitan competencia, pero cuya infracción determina la inconstitucionalidad de la ley sometida a examen". ${ }^{15}$

No obstante, hay que tener cuidado en utilizar la expresión bloque de la constitucionalidad del mismo modo que se emplea en el ordenamiento jurídico

\footnotetext{
11 VV.AA. (2014).

12 CALDERA INFANTE (2012).

${ }^{13}$ HOYOS (1992), p. 105.

${ }^{14}$ Hay que tener en cuenta que "[E]n ocasiones, también se han incorporado legislación básica o reglamentos de las asambleas parlamentarias, pero la jurisprudencia no ha sido consistente en esa inclusión. Sin embargo, la doctrina ha servido para que España supere la noción formalista que ha tenido la Constitución al poder contar con elementos más amplios para decidir la constitucionalidad de las leyes. Además, el bloque ha podido contribuir a delimitar las competencias entre el Estado y las Comunidades Autónomas, armonía que ha sido necesaria para consolidar la democracia española en cuanto a las diferencias de nacionalidades dentro de España". CALDERA INFANTE (2012).

15 Rubio LLORENTE (1989), p. 19.
} 
Villanueva - La regulación de la justicia ...

francés e incluir en este contexto a los Estatutos de Autonomía como normas del mismo, tal y como se ha hecho en alguna ocasión, ya que dicho concepto nace en Francia para dar solución a un problema, el cual era la inclusión por parte del Texto Constitucional de otros textos normativos ya existentes y que el poder constituyente considera que deben ser tratados al mismo nivel de la Constitución, lo cual supone que esas normas no podrán ser objeto de recurso de inconstitucionalidad. En el caso español no se da esta situación, por lo que podemos decir que no existe bloque de la constitucionalidad stricto sensu, ya que el poder constituyente no incluyó otros textos normativos dentro del cuerpo constitucional, sin embargo es la propia Carta Magna la que sienta las bases para la creación de los Estatutos de Autonomía, primero en su artículo 2, después en el Título VIII y finalmente en distintas disposiciones transitorias. Dicho esto, se llega a una sencilla conclusión, y es que los Estatutos de Autonomía pueden ser juzgados sin ningún problema por el Tribunal Constitucional, e incluso pueden ser declarados inconstitucionales, cosa que no podría ocurrir en caso de que formasen parte de un bloque de constitucionalidad como el original francés. Es por ello que con la sentencia que será examinada en el presente estudio de forma mayoritaria, la STC $31 / 2010^{16}$, al juzgar al Estatuto de Autonomía de Cataluña, rompe definitivamente con esta idea de considerar que el bloque de la constitucionalidad en Francia y en España son iguales. ${ }^{17}$

Cosa distinta, es lo establecido en el artículo 28 de la Ley Orgánica del Tribunal Constitucional, que dice literalmente que "[P]ara apreciar la conformidad o disconformidad con la Constitución de una Ley, disposición o acto con fuerza de Ley del Estado o de las Comunidades Autónomas, el Tribunal considerará,

16 Tribunal Constitucional de España, 99 Diputados del Grupo Parlamentario Popular del Congreso (2010): 28 de junio de 2010 (Función y contenido constitucional del Estatuto de Autonomía de Cataluña - Recurso de inconstitucionalidad). Rol No 31/2010, en página electrónica del Tribunal Constitucional http://hj.tribunalconstitucional.es/HJ/es/Resolucion/Show/6670.

17 No hay que olvidar que, a pesar de las críticas que se puedan realizar a las sentencias, el pronunciamiento desactiva la norma autonómica tal y como fue concebida, y a pesar de considerarse que las normas estatutarias forman parte del bloque de la constitucionalidad, si el español fuera como el francés, esto no podría suceder. Sumado a esto, aún en el caso de considerar los Estatutos de Autonomía como normas equivalentes a una Constitución para el territorio de la Comunidad Autónoma de que se trate equiparable al sistema de estado federal, tal y como ha sugerido algún autor, y aun teniendo en cuenta que ha sido una norma sometida a referéndum, esto no impediría al Tribunal Constitucional declarar su inconstitucionalidad, ya que si giramos la vista al derecho comparado, siguiendo al profesor Víctor Ferrelles Comella, en la cuna de la Justicia Constitucional, es decir, en Estados Unidos, los jueces se han visto obligados a pronunciarse en alguna ocasión acerca de la validez de normas salidas de procedimientos de democracia directa, sin que haya resultado extraño que de ese pronunciamiento haya procedido una declaración de inconstitucionalidad y por lo tanto la nulidad de la norma, como puede ser la sentencia Romers vs Evans (Corte Suprema de los Estados Unidos, Romers vs Evans (1996): 20 de mayo de 1996 (Derechos parejas homosexuales). Rol No 517 US 620 en página de la Corte de justicia https://supreme.justia.com/cases/federal/us/517/620/case.html), que declara la invalidez de la reforma producida en la Constitución de Colorado que había sido aprobada en referéndum. FERRELLES COMELLA (2010), pp. 75-76. 
además de los preceptos constitucionales, las Leyes que, dentro del marco constitucional, se hubieran dictado para delimitar las competencias del Estado y las diferentes Comunidades Autónomas o para regular o armonizar el ejercicio de las competencias de éstas". Esto implica que tanto las normas estatales como las autonómicas pueden acompañar a la Constitución en su misión de juzgar la constitucionalidad de una norma, pero evidentemente, esto no crea ningún bloque de la constitucionalidad como el originario francés ${ }^{18}$ se trata, en definitiva, de una cosa diferente. ${ }^{19}$

En segundo término, otra consideración a tener en cuenta relacionada con la sentencia en general, es uno de los aspectos que ha sido más criticados desde el punto de vista doctrinal.

Cabe recordar que el Tribunal Constitucional, al resolver un recurso de inconstitucionalidad, puede, por un lado, estimar la impugnación y por tanto hacer una declaración de inconstitucionalidad, lo cual supondría la nulidad de lo impugnado, pero por otro lado, puede utilizar la técnica de la interpretación conforme.

Esta técnica de la interpretación conforme encuentra su fundamento en el principio jurídico favor legis. García de Enterría ha afirmado que el principio de interpretación conforme a la Constitución tiene su origen en el proceso de constitucionalización de las leyes, y habla de una "presunción de constitucionalidad de las leyes", aclarando que esto no implica afirmar que una ley es constitucional hasta que sea declarada inconstitucional sino que supone "primero, una confianza otorgada al legislativo en la observancia y en la interpretación correcta de los principios de la Constitución; en segundo término, que una ley no puede ser declarada inconstitucional más que cuando no exista "duda razonable" sobre su contradicción con la Constitución; tercero, que cuando una ley esté redactada en términos tan amplios que pueda permitir una interpretación inconstitucional habrá que presumir que, siempre que sea "razonablemente posible", el legislador ha sobreentendido que la interpretación

\footnotetext{
18 Sintetizando la idea expuesta, nos encontramos con que el bloque de la constitucionalidad francés, está formado por una serie de normas que la propia Constitución francesa nombra y situa en la misma situación que su Lex Superior, por lo que van a ser jerárquicamente iguales. En España, por el contrario, la Constitución no hace mención a otras normas de esta forma, por lo que, todas las normas autonómicas y estatales, van a situarse jerárquicamente debajo de la Carta Magna, y si bien es cierto que en los juicios de constitucionalidad, si procede, podrán ser empleadas para apoyar la declaración de conformidad o disconformidad con la Constitución, ello no les otorga la misma posición que ésta última, y en caso de contradecirla podrán ser objeto de recurso y juzgadas por el Alto Tribunal. Dicho esto, tenemos que en España, al contrario que en Francia, el bloque de la constitucionalidad se refiere a normas que pueden servir para controlar la constitucionalidad de otras, pero sin que tengan el mismo rango que la propia Constitución y sin que posean ningún privilegio por formar parte del bloque, pudiendo ser asi mismas juzgadas.

${ }^{19}$ Es necesario añadir que tal y como señala Flórez Turrado, en esta sentencia, el Tribunal se limita a realizar su función interpretativa apelando únicamente a la Constitución, contradiciendo en cierta medida lo establecido en este artículo 28.1 Ley Orgánica del Tribunal Constitucional. FlórEZ TURRADO (2012), p. 241.
} 
con la que habrá de aplicarse dicha ley es precisamente la que permita mantenerse dentro de los límites constitucionales". ${ }^{20}$

Por su parte, el Tribunal Constitucional alemán se ha pronunciado acerca de los límites que tiene la interpretación conforme, en sus propias palabras "la interpretación conforme encuentra sus límites allí donde entra en contradicción con el texto de la norma y la voluntad del legislador claramente reconocida". ${ }^{21}$

En la sentencia $31 / 2010,{ }^{22}$ se hace un abuso manifiesto de la técnica que se acaba de explicar, no solo por corromper su origen, sino también por saltarse sus límites. A lo largo de la resolución puede observarse como el propio tribunal hace interpretaciones que implican, no elegir entre dos posibles sentidos que pueda tener el precepto en cuestión, sino contradecir por completo su significado. La interpretación conforme supone elegir entre varias interpretaciones que existen, teniendo en cuenta el texto del precepto, de tal forma que se opte por la interpretación que es compatible con el texto constitucional, sin embargo, lo que aquí se hace es cambiar el texto de algunos artículos, lo cual es completamente inaceptable, ya que lo que debería haberse hecho es proceder a una declaración de inconstitucionalidad.

A lo largo de esta sentencia del Estatuto de Autonomía catalán, se ven afectados por declaraciones de inconstitucionalidad 14 artículos, y un número bastante más elevado, concretamente 76 artículos, ${ }^{23}$ son objeto de interpretaciones conformes, que es la forma utilizada para echar por tierra el Estatuto. A lo largo de este estudio se hará un análisis crítico del tratamiento que ha realizado el Tribunal Constitucional respecto del Estatuto en la parte relativa a la Justicia, parte muy importante, porque es el bloque de la sentencia que se ha visto más afectado por las declaraciones de inconstitucionalidad ${ }^{24}$ a la vez que se hacen algunas interpretaciones conformes.

Como punto y final a estas consideraciones previas, es necesario señalar otra cosa incomprensible para una gran parte del sector doctrinal, y es que no todas las modificaciones realizadas por el Alto Tribunal, ya sea mediante declaraciones de inconstitucionalidad o mediante la técnica de la interpretación conforme, son llevadas al fallo. Esto se ha intentado explicar de la única forma que a uno se le viene a la mente, y esta es para intentar suavizar el impacto de llevar

\footnotetext{
20 GARCÍA DE ENTERRÍA (1981), p. 103.

${ }^{21}$ BVerfGE 110, 226.

22 Tribunal Constitucional de España, 99 Diputados del Grupo Parlamentario Popular del Congreso (2010): 28 de junio de 2010 (Función y contenido constitucional del Estatuto de Autonomía de Cataluña - Recurso de inconstitucionalidad). Rol No 31/2010, en página electrónica del Tribunal Constitucional http://hj.tribunalconstitucional.es/HJ/es/Resolucion/Show/6670.

23 Cabe señalar que de estos 76 artículos que son sometidos a una interpretación conforme, solamente 27 de ellos son llevados al fallo, mientras que 49 se dejan en el cuerpo de la sentencia.

246 de las 14 a las que se ha hecho mención.
} 
todas las modificaciones al fallo, de tal forma que se diera apariencia de que son menos los preceptos que se han visto afectados.

\section{El tratamiento de la Justicia en el Estatuto catalán y en la doctrina del Tribunal Constitucional}

Como se ha señalado en la introducción, lo que aquí se va a examinar, no es el tratamiento jurídico que se da a todo el Estatuto, sino únicamente se tratará lo relativo a la Justicia, lo cual se encuentra regulado en el Capítulo I, II y III del Título III del Estatuto, que se intitula "Del Poder judicial en Cataluña", y que es tratado en los fundamentos jurídicos 42 a 55 .

Lo primero que cabe señalar en el análisis jurídico objeto de este estudio, es la posibilidad de transferir a las Comunidades Autónomas competencias sobre lo que se ha llamado Administración de la Administración de Justicia, pero teniendo presente que la competencia sobre la Administración de Justicia le corresponde al Estado. Esta posibilidad la otorga el Tribunal Constitucional en el primer fundamento jurídico referido al Título III del Estatuto. En este sentido es necesario saber que esta posible transferencia que se nos nombra, no es algo nuevo, sino que viene a ser una jurisprudencia reiterada del Tribunal. Lo que se hace a lo largo de esta parte de la sentencia, es determinar si los preceptos del Estatuto que han sido impugnados, entran dentro de la competencia autonómica o forman parte del contenido reservado al Estado.

Antes de iniciar el análisis de los preceptos impugnados, es necesario contestar a una importante cuestión: ¿Qué se entiende por Administración de la Administración de Justicia? Para responder a esta cuestión básica, se debe acudir a la Constitución Española de 1978, la cual, en su artículo 149.1 establece las competencias exclusivas del Estado, y concretamente se dice que el Estado tiene competencia exclusiva en materia de Administración de Justicia (artículo 149.1.5). Una vez determinado el punto de partida, debe señalarse que este precepto se está refiriendo a los órganos y funciones que integran el Poder Judicial, no incluyendo en dicho artículo a los medios auxiliares, ya sean personales o materiales, que están al servicio de este Poder pero no integrados de forma estricta en él. ${ }^{25}$ Por ello ha de decirse que son estos medios auxiliares lo que conforman la llamada Administración de la Administración de Justicia. Dado que dentro de las competencias exclusivas del Estado, solo se incluye el Poder Judicial strictu sensu, en base al artículo 149.3 y el 152.1, se entiende que los medios auxiliares, al quedar fuera de la competencia exclusiva, quedan a disposición de las Comunidades Autónomas. En este mismo sentido se ha pronunciado el Tribunal Constitucional a lo largo de distintas sentencias que forman una reiterada jurisprudencia en relación al tema y que comienzan con la STC 56/1990, de 29 de marzo, dónde se

25 Dicho de otro modo, solo se considera como competencia exclusiva del Estado, aquellos elementos del Poder Judicial que forman su núcleo esencial. 
Villanueva - La regulación de la justicia ...

afirmó que, siempre con ciertos límites y excepciones, las Comunidades Autónomas podían tener competencias en este ámbito a través de cláusulas subrogatorias contenidas en sus Estatutos de Autonomía.

Asimismo, el Tribunal Constitucional dice, en el fundamento jurídico 42 de la sentencia $31 / 2010,{ }^{26}$ que tanto la unidad de jurisdicción como la unidad del Poder Judicial no se ven afectados por la estructura territorial del Estado. Además realiza una comparación del Estado Autonómico con el Estado Federal, señalando que "una de las características definitorias del Estado autonómico, por contraste con el federal, es que su diversidad funcional y orgánica no alcanza en ningún caso a la jurisdicción". "Hay que aclarar que esta afirmación es completamente inexacta, ya que tal y como señala Aparicio Pérez, existen algunos sistemas federales que no presentan diversidad judicial territorial, ni funcional ni orgánica, como son los casos de Austria o Suiza. ${ }^{28}$

Procediendo ahora con el estudio de los artículos que nos ocupan, el primero de los preceptos que se impugna es el artículo 95, el cual abre el Capítulo I que lleva por rúbrica "El Tribunal Superior de Justicia y el Fiscal o la Fiscal Superior de Cataluña". Este primer precepto reza del siguiente modo:
Articulo 95 El Tribunal Superior de Justicia de Cataluña
1. El Tribunal Superior de Justicia de Cataluña es el órgano jurisdiccional en que culmina la organización judicial en Cataluña y es competente, en los términos establecidos por la ley orgánica correspondiente, para conocer de los recursos y de los procedimientos en los distintos órdenes jurisdiccionales y para tutelar los derechos reconocidos por el presente Estatuto. En todo caso, el Tribunal Superior de Justicia de Cataluña es competente en los órdenes jurisdiccionales civil, penal, contencioso-administrativo, social y en los otros que puedan crearse en el futuro.
2. El Tribunal Superior de Justicia de Cataluña es la última instancia jurisdiccional de todos los procesos iniciados en Cataluna, asi como de todos los recursos que se tramiten en su ámbito territorial, sea cual fuere el derecho invocado como aplicable, de acuerdo con la Ley Orgánica del Poder Judicial y sin perjuicio

\footnotetext{
26 Tribunal Constitucional de España, 99 Diputados del Grupo Parlamentario Popular del Congreso (2010): 28 de junio de 2010 (Función y contenido constitucional del Estatuto de Autonomía de Cataluña - Recurso de inconstitucionalidad). Rol N ${ }^{\circ} 31 / 2010$, en página electrónica del Tribunal Constitucional http://hj.tribunalconstitucional.es/HJ/es/Resolucion/Show/6670.

27 A este respecto es también interesante el hacer mención a la STC 137/2010 (Tribunal Constitucional de España, Defensor del Pueblo (2010): 16 de diciembre de 2010 (Preceptos varios del Estatuto de Autonomía de Cataluña - Recurso de inconstitucionalidad). Rol No 137/2010, en página electrónica del Tribunal Constitucional http://hj.tribunalconstitucional.es/HJ/es/Resolucion/Show/6776). Esta sentencia es posterior a la que se está analizando, pero guarda una estrecha relación, ya que se refiere al mismo tema, en ella, a tenor del Fundamento Jurídico 8, se establece que la materia de Administración de Justicia le corresponde al Estado, y que lo dispuesto en un Estatuto no puede de ningún modo condicionar o limitar al legislador orgánico puesto que la Ley Orgánica del Poder Judicial es la única que puede regular la materia de Administración de justicia.

28 APARICIO PÉREZ (2010), p. 200.
} 
de la competencia reservada al Tribunal Supremo para la unificación de doctrina. La Ley Orgánica del Poder Judicial determinará el alcance y contenido de los indicados recursos.

3. Corresponde en exclusiva al Tribunal Superior de Justicia de Cataluña la unificación de la interpretación del derecho de Cataluña.

4. Corresponde al Tribunal Superior de Justicia de Cataluña la resolución de los recursos extraordinarios de revisión que autorice la ley contra las resoluciones firmes dictadas por los órganos judiciales de Cataliña.

5. El Presidente o Presidenta del Tribunal Superior de Justicia de Cataluña es el representante del poder judicial en Cataluña. Es nombrado por el Rey, a propuesta del Consejo General del Poder Judicial y con la participación del Consejo de Justicia de Cataluña en los términos que determine la Ley Orgánica del Poder Judicial. El Presidente o Presidenta de la Generalitat ordena que se publique su nombramiento en el «Diari Oficial de la Generalitat de Catalunya».

6. Los Presidentes de Sala del Tribunal Superior de Justicia de Cataluña son nombrados a propuesta del Consejo General del Poder Judicial y con la participación del Consejo de Justicia de Cataluña en los términos que determine la Ley Orgánica del Poder Judicial.

El fundamento jurídico 43 es el que empieza a desarrollar la impugnación de este precepto. El Tribunal considera que lo establecido en el apartado primero del artículo 95, donde se establece que el Tribunal Superior de Justicia tiene la condición de órgano en el que culmina la organización judicial en Cataluña, equivale a lo establecido en el artículo $152.1 \mathrm{CE}$ y sus competencias y funciones vienen determinadas por la Ley Orgánica del Poder Judicial. Además señala que tal y como se dice en el final de ese apartado del artículo, los Tribunales Superiores de Justicia son competentes en todos los órdenes jurisdiccionales que existan, siendo esto fruto de tener la consideración de órgano en el que culmina la organización judicial en cada territorio, pero teniendo en cuenta que es competencia estatal la determinación de los órdenes jurisdiccionales y la competencia de los Tribunales Superiores de Justicia. ${ }^{29} \mathrm{El}$ Tribunal también aclara ${ }^{30}$ que la relación que se hace en el Estatuto del Tribunal Superior de Justicia como garante de los derechos estatutarios, no puede suponer que se introduzcan innovaciones procesales ni que se alteren las reglas procesales comúnmente aplicables, añadiendo que la previsión que hace el Estatuto se materializará si es establecido por el Estado en su caso. Todo ello lleva al Alto Tribunal a desestimar la impugnación de este artículo 95.1.

Respecto a este apartado primero, hay que decir que el Estatuto de Autonomía de Cataluña establece una norma directa sobre la organización del

\footnotetext{
${ }^{29}$ Que lo establecerá mediante la Ley Orgánica del Poder Judicial.

${ }^{30}$ Aunque en la misma sentencia ya lo había mencionado en los fundamentos jurídicos 26 y 27 , referidos a los artículos. 37 y 38 del Estatuto de Autonomía de Cataluña. Respecto de este último artículo 38, concretamente de su apartado segundo, hay un pronunciamiento del magistrado Rodríguez Arribas en su voto particular señalando que es inconstitucional puesto que no es admisible que un Estatuto condicione o supla las leyes orgánicas y leyes procesales que son una competencia exclusiva del Estado. Esto mismo podría aplicarse de cara a este artículo 95.
} 
Poder Judicial determinando el órgano superior de la misma, al mismo tiempo también establece unas competencias del órgano de forma directa también, con una clara pretensión de regularlas, lo cual es sin duda una materia estatal a tenor del mandato constitucional del artículo 149.1.5 CE y, como consecuencia del precepto constitucional, de la Ley Orgánica del Poder Judicial. ${ }^{31}$ Finalmente el artículo parece que crea un recurso de amparo a nivel autonómico para salvar los derechos contenidos en el Estatuto, el cual no existe en nuestro ordenamiento jurídico, y que exigiría una regulación estatal para su existencia, una regulación que vincularía no solo a Cataluña, sino al resto de Comunidades Autónomas. Aún así, este hipotético recurso de amparo autonómico tendría, en todo caso, que exceptuar aquellos supuestos en los que se pueda acudir al Tribunal Constitucional por coincidir la vulneración de un derecho estatutario con la de un derecho fundamental.

El Fundamento Jurídico 44 está referido al apartado segundo del mismo artículo 95 del Estatuto, el cual señala que el Tribunal Superior de Justicia de Cataluña es la última instancia jurisdiccional de todos los procesos que se inicien en la Comunidad Autónoma, respecto de la cual, el Tribunal Constitucional dice que el hecho de que la organización judicial en la Comunidad Autónoma culmine con el Tribunal Superior de Justicia no implica que todos los procesos, cualquiera que sea el orden jurisdiccional, terminen en dicho Tribunal. No obstante, lo destacable del precepto examinado, es la referencia que se hace a la competencia del Tribunal Supremo en materia de unificación de doctrina, y respecto de esta mención el Tribunal Constitucional decide hacer una interpretación conforme, estableciendo que el artículo no debe entenderse en sentido literal, puesto que incluye también la unificación de la aplicación y la interpretación del Derecho que se alcanzan mediante las vías establecidas en la Ley Orgánica del Poder Judicial. Aquí puede apreciarse como el Tribunal Constitucional contradice el sentido literal del artículo, por lo que, a juicio del autor del presente trabajo, debería haber sido declarado inconstitucional, ya que como el propio Tribunal dice en su argumentación, la Ley Orgánica del Poder Judicial es la única norma constitucionalmente habilitada para determinar las funciones del Tribunal Supremo.

Este artículo, al dejar relegado el papel del Tribunal Supremo a la unificación de doctrina, que ni siquiera afecta a la cosa juzgada, supone una clara vulneración del artículo 123.1 CE, ya que este precepto establece la jurisdicción en toda España del Tribunal Supremo, siendo el órgano superior en todos los órdenes salvo en lo relativo a garantías constitucionales. En el precepto del Estatuto parece que se contradice esto y que sitúa al Tribunal Superior de Justicia de Cataluña como el órgano de última instancia de todos los procesos iniciados en Cataluña, lo cual no es cierto, ya que el Tribunal Supremo puede conocer de estos casos, siendo incomprensible que un Estatuto de Autonomía pueda establecer competencias al

\footnotetext{
${ }^{31}$ Es por ello que considero que la remisión a la ley estatal que hace el precepto, no es suficiente para salvar la vulneración del precepto constitucional.
} 
Tribunal Supremo. ${ }^{32}$ Además, es necesario añadir que esta distribución de competencias que hace el Estatuto entre Tribunal Superior de Justicia y Tribunal Supremo, resultaría contrario a la reserva de la Ley Orgánica del Poder Judicial para tal reparto y asignación a tenor de lo dispuesto en los artículos 122, 149.1.5 y 6 CE.

El apartado tercero del artículo 95 es el único que no ha sido sometido a examen por no padecer vicios de inconstitucionalidad, de ahí que no haya sido objeto del recurso. En verdad cabe precisar que no ofrece problemas de constitucionalidad ya que es acorde a la Disposición Adicional $1^{\mathrm{a}}$ y al artículo 148.1.8 CE.

El apartado cuarto, aparece analizado en el fundamento jurídico 45; este apartado del artículo establece que al Tribunal Superior de Justicia de Cataluña le corresponde la resolución de los recursos extraordinarios de revisión que autorice la ley contra las resoluciones firmes que se dicten por los órganos de la Comunidad Autónoma. La realidad es que este artículo determina la competencia del Tribunal Superior de Justicia de Cataluña para una materia concreta (recursos extraordinario de revisión), y eso es competencia reservada al Estado (artículos 149.1.5 y $6 \mathrm{CE}$ ). También encontramos que el artículo hace referencia a la ley para que se determinen los recursos, sin especificar qué ley, pero aun así, la norma autonómica -que recordemos que la Comunidad Autónoma no es competente- decide directamente que órgano ha de resolver. Por su parte el Tribunal vuelve a utilizar la técnica de la interpretación. Esta interpretación, supone que este precepto no puede entenderse como una atribución de competencia, ya que ello le corresponde determinarlo a la ley estatal, que no puede ser otra que la Ley Orgánica del Poder Judicial. Por ello y siempre que se siga la interpretación que acaba de darse, se desestima la impugnación del precepto.

En que se refiere al análisis de los dos últimos apartados del artículo 95, es decir, el 95.5 y 95.6, siguiendo la estructura establecida en la sentencia, se hace junto con el análisis del artículo 97 al tenor de lo establecido en el fundamento jurídico 45. Lo importante en estos dos apartados es la mención que se hace al Consejo de Justicia, un órgano al que se refiere el artículo 97 y que es declarado inconstitucional, por lo que por conexión con esta inconstitucionalidad y con el 98.2 inciso a), referido a las atribuciones de este órgano, se declaran inconstitucionales los apartados 5 y 6 del artículo $95 .^{33}$

\footnotetext{
32 En este sentido similar se pronuncia el magistrado Rodríguez Arribas en un voto particular, señalando una vulneración del artículo $123 \mathrm{CE}$.

${ }^{3}$ Hay que aclarar que este artículo 95, ha sido objeto de mención en los votos particulares, de tal forma que el magistrado Conde Martín de Hijas considera que la totalidad del artículo 95 debería haber sido declarado inconstitucional por invadir una competencia constitucional a tenor de lo establecido en el artículo 122.1 CE.
} 
Villanueva - La regulación de la justicia ...

Ahora se procederá a examinar el artículo 96 del Estatuto de Autonomía, referido al Fiscal o la Fiscal Superior de Cataluña, el cual sirve de cierre de este Capítulo I del Título III. Este artículo dice:

Articulo 96 El Fiscal o la Fiscal Superior de Cataluña

1. El Fiscal o la Fiscal Superior de Cataluña es el Fiscal Jefe o la Fiscal Jefa del Tribunal Superior de Justicia de Cataluña representa al Ministerio Fiscal en Cataluña, y será designado en los términos que establezca su estatuto orgánico.

2. El Presidente o Presidenta de la Generalitat ordena la publicación del nombramiento del Fiscal o la Fiscal Superior de Cataluña en el «Diari Oficial de la Generalitat de Catalunyas.

3. El Fiscal o la Fiscal Superior de Cataluña debe enviar una copia de la memoria anual de la Fiscalía del Tribunal Superior de Justicia de Cataluña al Gobierno, al Consejo de Justicia de Cataluña y al Parlamento, y debe presentarla ante este dentro de los seis meses siguientes al día en que se hace pública.

4. Las funciones del Fiscal o la Fiscal Superior de Cataluña son las que establece el Estatuto orgánico del Ministerio Fiscal. La Generalitat podrá celebrar convenios con el Ministerio Fiscal.

El fundamento jurídico 46 es el que se encarga de examinar todo este artículo. En lo referido a su apartado primero, es decir, el artículo 96.1, el Tribunal considera que es conforme a la Constitución, ya que no se altera su proceso de designación ni sus funciones institucionales que dependerán necesariamente del Estatuto Orgánico del Ministerio Fiscal.

En lo que se refiere al 96.2, este establece que el nombramiento del Fiscal o de la Fiscal Superior de Cataluña, será publicado en el Diario Oficial de la Comunidad Autónoma, lo cual a juicio del Tribunal, no incumple con los mandatos constitucionales, sino que el perfeccionamiento del nombramiento se consigue mediante su publicación en el Boletín Oficial del Estado, y que la publicación en el Diario Oficial de la Comunidad Autónoma simplemente hay que entenderlo como un medio para su mayor conocimiento público.

El apartado tercero del artículo 96 se refiere a la presentación de una copia de la memoria anual de la Fiscalía del Tribunal Superior de Justicia a distintas instituciones autonómicas. Aquí el Tribunal Constitucional entiende que esto solo puede tener un carácter informativo, y que no puede suponer que la Comunidad Autónoma de Cataluña asuma funciones de control sobre la actuación del Fiscal Superior.

Finalmente, y de forma breve, el apartado 4 del artículo establece la posibilidad de celebrar convenios con el Ministerio Fiscal, pero a juicio del Tribunal, esto no altera ni la posición ni la autonomía institucional del Ministerio Fiscal.

Por todo ello el Tribunal Constitucional desestima la impugnación de este artículo. 
Hay que aclarar que en el tema de la fiscalía, es donde menos han sido acertadas las pretensiones de los recurrentes ya que el Tribunal Constitucional en este caso, simplemente se limita a realizar una serie de aclaraciones que no llegan a ser interpretaciones conformes, sino meras puntualizaciones que realiza el máximo intérprete de la Constitución. Sin embargo, no por ello estas aclaraciones se ven desprovistas de significación, ya que con ellas se resta valor a lo previsto en la norma estatutaria, y es que el Estatuto de Autonomía no puede ofrecer regulación novedosa del órgano porque carece de competencia para ello si atendemos a la configuración legal y constitucional del mismo. Por ello, en el examen de este precepto poco más puede añadirse, ya que el propio artículo 96 hace una remisión al Estatuto Orgánico sin que se modifique su régimen jurídico de forma material ${ }^{34}$.

En lo respectivo al Capítulo II del Título III del Estatuto de Autonomía de Cataluña, este lleva por rúbrica "El Consejo de Justicia de Cataluña", y se inicia con el artículo $97^{35}$ que tiene la misión de definirlo como el órgano del poder judicial en la Comunidad Autónoma, actuando como órgano desconcentrado del Consejo General del Poder Judicial sin perjuicio de las competencias atribuidas por la Ley Orgánica del Poder Judicial a este último.

\section{Artículo 97 El Consejo de Justicia de Cataluña. \\ El Consejo de Justicia de Cataluña es el órgano de gobierno del poder judicial en Cataluña. Actúa como órgano desconcentrado del Consejo General del Poder Judicial, sin perjuicio de las competencias de este último, de acuerdo con lo previsto en la Ley Orgánica del Poder Judicial.}

Por primera vez dentro de este Título III, el Tribunal Constitucional declara inconstitucional un artículo de forma íntegra. Según el Alto Tribunal, la configuración que el Estatuto da a este Consejo de Justicia no es conforme a la Constitución, dado que le confiere funciones como órgano de gobierno del Poder Judicial en la Comunidad Autónoma, y en atención al artículo 122 CE ningún órgano salvo el Consejo General del Poder Judicial puede tener esas funciones. Sin embargo, el Tribunal da una vía de escape al legislador orgánico estatutario señalando que estos órganos autonómicos podrían ser constitucionales si estuviesen regulados por la Ley Orgánica del Poder Judicial. ${ }^{36}$ No obstante, aquí es necesario hacer referencia a distintas opiniones como la de Tur Ausina y Álvarez Conde que consideran que "ello no es suficiente, pues, en buena técnica jurídica,

\footnotetext{
34 Hay que advertir que el magistrado Conde Martín de Hijas, es el único que hace referencia expresa a este artículo 96 en su voto particular señalando que debe ser tachado de inconstitucionalidad por incurrir el Estatuto en un exceso de competencia.

${ }^{35}$ Este artículo es el único que se declara inconstitucional de forma íntegra.

${ }^{36}$ No podemos olvidarnos de hacer mención a la crítica que hacen tres magistrados en sus votos particulares respecto de este artículo. Concretamente se trata del magistrado Conde Martín de Hijas, Delgado Barrio y Rodríguez Arribas, los tres consideran que no se debió intentar salvar la constitucionalidad del órgano y por lo tanto debió declararse inconstitucional no sólo este artículo sino también todo lo que guarda una relación con él.
} 
Villanueva - La regulación de la justicia ...

se requiere la voluntad del CGPJ para proceder a desconcentrar sus funciones y competencias. La LOPJ puede prever su existencia, pero nada más. E incluso es posible la existencia de un órgano desconcentrado del CGPJ sin previsión expresa de la propia LOPJ".

Por su parte, y siguiendo en este Capítulo II del Estatuto de Autonomía de Cataluña, el artículo 98 establece las atribuciones de este Consejo de Justicia, el artículo 99 su composición, organización y funcionamiento y el artículo 100 el control de los actos de este órgano. Así pues:

\section{Articulo 98 Atribuciones}

1. Las atribuciones del Consejo de Justicia de Cataluña son las que establecen el presente Estatuto, la Ley Orgánica del Poder Judicial, las leyes que apruebe el Parlamento y las que, si procede, le delegue el Consejo General del Poder Judicial.

2. Las atribuciones del Consejo de Justicia de Cataluña respecto a los órganos jurisdiccionales situados en el territorio de Cataluña son, conforme a lo previsto en la Ley Orgánica del Poder Judicial, las siguientes:

a) Participar en la designación del Presidente o Presidenta del Tribunal Superior de Justicia de Cataluña, así como en la de los Presidentes de Sala de dicho Tribunal Superior y de los Presidentes de las Audiencias Provinciales.

b) Proponer al Consejo General del Poder Judicial y expedir los nombramientos y los ceses de los Jueces y Magistrados incorporados a la carrera judicial temporalmente con funciones de asistencia, apoyo o sustitución, asi como determinar la adscripción de estos Jueces y Magistrados a los órganos judiciales que requieran medidas de refuerzo.

c) Instruir expedientes y, en general, ejercer las funciones disciplinarias sobre Jueces y Magistrados en los términos previstos por las leyes.

d) Participar en la planificación de la inspección de juzgados y tribunales, ordenar, en su caso, su inspección y vigilancia y realizar propuestas en este ámbito, atender a las órdenes de inspección de los juzgados y tribunales que inste el Gobierno y dar cuenta de la resolución y de las medidas adoptadas.

e) Informar sobre los recursos de alzada interpuestos contra los acuerdos de los órganos de gobierno de los tribunales y juagados de Cataluñ.

f) Precisar y aplicar, cuando proceda, en el ámbito de Cataluña, los reglamentos del Consejo General del Poder Judicial.

g) Informar sobre las propuestas de revisión, delimitación y modificación de las demarcaciones territoriales de los órganos jurisdiccionales y sobre las propuestas de creación de secciones y juzgados.

b) Presentar una memoria anual al Parlamento sobre el estado y el funcionamiento de la Administración de Justicia en Cataluña.

i) Todas las funciones que le atribuyan la Ley Orgánica del Poder Judicial y las leyes del Parlamento, y las que le delegue el Consejo General del Poder Judicial.

\footnotetext{
${ }^{37}$ Tur Ausina y Álvarez Conde (2010), p. 206.
} 
3. Las resoluciones del Consejo de Justicia de Cataluña en materia de nombramientos, autorizaciones, licencias y permisos deben adoptarse de acuerdo con los criterios aprobados por el Consejo General del Poder Judicial.

4. El Consejo de Justicia de Cataluña, a través de su presidente o presidenta, debe comunicar al Consejo General del Poder Judicial las resoluciones que dicte y las iniciativas que emprenda y debe facilitar la información que le sea pedida.

Articulo 99 Composición, organización y funcionamiento

1. El Consejo de Justicia de Cataluña está integrado por el Presidente o Presidenta del Tribunal Superior de Justicia de Cataluña, que lo preside, y por los miembros que se nombren, de acuerdo con lo previsto por la Ley Orgánica del Poder Judicial, entre Jueces, Magistrados, Fiscales o juristas de reconocido prestigio. El Parlamento de Cataluña designa a los miembros del Consejo que determine la Ley Orgánica del Poder Judicial. Inciso «por el Presidente o Presidenta del Tribunal Superior de Justicia de Cataluña, que lo preside, y» articulo 99.1 declarado inconstitucional, y por lo tanto, nulo por Sentencia del Tribunal Constitucional de 28 de junio de 2010.

2. El Consejo de Justicia de Cataluña aprueba su reglamento interno de organización y funcionamiento, de acuerdo con la normativa aplicable.

Artículo 100 Control de los actos del Consejo de Justicia de Cataluña

1. Los actos del Consejo de Justicia de Cataluña serán recurribles en alzada ante el Consejo General del Poder Judicial, salvo que hayan sido dictados en el ejercicio de competencias de la Comunidad Autónoma.

2. Los actos del Consejo de Justicia de Cataluña que no sean impugnables en alzada ante el Consejo General del Poder Judicial pueden impugnarse jurisdiccionalmente en los términos establecidos en las leyes.

La lógica jurídica nos lleva a pensar que, dado que el órgano en cuestión ha sido declarado inconstitucional, todo lo relativo a él, ${ }^{38}$ debería igualmente adolecer de este vicio, pero el Tribunal Constitucional vuelve a sorprendernos en su argumentación. Lo que hace es declarar inconstitucionales algunos de los preceptos, concretamente, aparte del ya mencionado artículo 97, se declaran contrarios a la Constitución el artículo 98.2.a].b].c].d] y .e], el artículo 98.3, el artículo 99.1 y el artículo 100.1, sin olvidarnos del artículo 95 apartados 5 y 6 del Capítulo I. Por lo tanto, lo que hace el Tribunal es anular algunas de las menciones a este órgano, así como parte de sus funciones y algunos elementos de su organización y su estructura interna, adoptando una solución algo caótica e incumpliendo el principio de congruencia propio de las normas jurídicas, dando como resultado, tal y como señala el profesor Roberto Blanco Valdés "que el Estatuto acabe regulando parcialmente un órgano que jurídicamente no existe al

\footnotetext{
${ }^{38}$ Cabe recordar que el artículo 95 apartados 5 y 6, también se referían precisamente a este Consejo
} de Justicia de Cataluña. 
Villanueva - La regulación de la justicia ...

haber sido creado por un precepto que la sentencia ha declarado inconstitucional y ha procedido a anular". ${ }^{39}$

Cabellos Espiérrez señala, de forma acertada, que la situación en la que se analizan estos artículos y la solución que se da, lleva a pensar que el propio Tribunal Constitucional considera la posibilidad de un órgano autonómico con funciones propias, cosa que no aparece contemplado en el Estatuto. Concretamente dice "realiza un deslinde entre funciones que podrían pertenecer a un Consejo de Justicia autonómico (no relacionado con el CGPJ y por ello no encargado del gobierno del poder judicial) y funciones que, por referirse o afectar a dicho gobierno, en ningún caso podría tener. Entre las primeras, sorprendentemente, incluye una (precisar y aplicar los reglamentos del CGPJ) que parece claro que tendría que estar con las segundas". ${ }^{40}$

Por ello se puede decir que solamente se van a mantener en el Estatuto como legítimas funciones del Consejo de Justicia, las competencias que tienen que ver con la ya mencionada "Administración de la Administración de Justicia". Lo que hace el Tribunal declarando algunos preceptos inconstitucionales y otros admitiéndolos como válidos, es cambiar la naturaleza del órgano, ya que en el Estatuto está considerado como un órgano que actúa por delegación del Consejo General del Poder Judicial y el Tribunal lo convierte en un órgano colaborador con el gobierno de la Comunidad Autónoma en el ejercicio de las competencias administrativas que puede tener. ${ }^{41}$

Por todo ello, queda patente que el Consejo de Justicia de Cataluña, ha quedado afectado de forma evidente, a pesar de ese intento de salvar su constitucionalidad cambiando su naturaleza y manteniendo constitucionales algunos preceptos relativos a él, que solo puede entenderse como un respeto hacia el legislador estatutario. No obstante, a pesar de ello, el órgano se ha desvirtuado sin ningún tipo de duda.

El Capítulo III lleva por rúbrica "Competencias de la Generalitat sobre la Administración de Justicia", se incluyen dentro de este capítulo los artículos 101 al 109. El artículo 101 reza de tal manera:

Artículo 101. Oposiciones y concursos

1. La Generalitat propone al Gobierno del Estado, al Consejo General del Poder

Judicial o al Consejo de Justicia de Cataluña, según corresponda, la convocatoria de oposiciones y concursos para cubrir las plazas vacantes de Magistrados, Jueces y Fiscales en Cataluña.

\footnotetext{
39 BLANCO VALDÉS (2010), p. 14.

40 CABEllos EspiÉrRez (2010), p. 208.

${ }^{41}$ Además es necesario hacer una mención al voto particular del magistrado Delgado Barrio, quien considera que la nulidad del artículo 97 debe arrastrar la nulidad de los artículos 98 y 99 de forma íntegra, no salvando el órgano como intenta hacer el Tribunal.
} 
2. El Consejo de Justicia de Cataluña convoca los concursos para cubrir plazas vacantes de Jueces y Magistrados en Cataluña en los términos establecidos en la Ley Orgánica del Poder Judicial.

3. Las pruebas de los concursos y las oposiciones regulados por el presente articulo, cuando se celebren en Cataluña, podrán realizarse en cualquiera de las dos lenguas oficiales a elección del candidato.

Respecto de este artículo, el Tribunal se ha pronunciado en el Fundamento Jurídico 50 diciendo que, dado que el Consejo de Justicia de Cataluña no tiene condición de órgano de gobierno del Poder Judicial, no puede convocar oposiciones y concursos para cubrir las plazas vacantes de Magistrados, Jueces y Fiscales en la Comunidad Autónoma, y por ello se declaran inconstitucionales tanto el apartado 2 del artículo 101 de forma íntegra como el inciso de "o al Consejo de Justicia de Cataluña" del artículo 101.1. Por su parte en relación con el 101.3, el Tribunal desestima su impugnación ya que no supone una obligación de utilizar el catalán, sino una manifestación del derecho que tienen los ciudadanos para relacionarse con la Administración en dicha lengua. También se señala que tanto en las oposiciones y concursos para el acceso a la carrera judicial como en lo referido a la promoción y traslado, el derecho de opción lingüística para sus candidatos serán ejercidos de acuerdo con lo establecido por el legislador orgánico del Poder Judicial, o lo que es lo mismo, por lo establecido en la Ley Orgánica del Poder Judicial.

dice:

El siguiente de los artículos de este nuevo capítulo es el artículo 102, que

Artículo 102 Del personal judicial y del resto del personal al servicio de la Administración de Justicia en Cataluña

1. Los Magistrados, Jueces y Fiscales que ocupen una plaza en Cataluña deberán acreditar un conocimiento adecuado y suficiente del catalán para hacer efectivos los derechos lingüisticos de los ciudadanos en la forma y con el alcance que determine la ley.

2. Los Magistrados, Jueces y Fiscales que ocupen una plaza en Cataluña deben acreditar un conocimiento suficiente del derecho propio de Cataluña en la forma y con el alcance que determine la ley.

3. En todo caso el conocimiento suficiente de la lengua y del derecho propios se valorará especifica y singularmente para obtener una plaza en los correspondientes concursos de traslado.

4. El personal al servicio de la Administración de Justicia y de la Fiscalía en Cataluña debe acreditar un conocimiento adecuado y suficiente de las dos lenguas oficiales que los bace aptos para ejercer las funciones propias de su cargo o puesto de trabajo.

A tenor de lo dicho por el Tribunal, la obligación de Magistrados, Jueces y Fiscales de tener un adecuado conocimiento del catalán, va a depender de lo establecido por la ley estatal que sea competente. Lo mismo ocurre con el apartado cuarto del 
Villanueva - La regulación de la justicia ...

mismo precepto, donde señala el Tribunal que no hay motivo para su inconstitucionalidad, ya que está establecido en términos generales y como consecuencia de la cooficialidad. ${ }^{42}$

En lo relativo al conocimiento del Derecho propio de Cataluña al que se hace referencia en el apartado segundo y tercero de este mismo artículo, dice el fundamento jurídico 51 que se trata ya de una obligación de Magistrados, Jueces y Fiscales españoles, ya que estos tienen como función la aplicación del derecho integrado en el Ordenamiento español. ${ }^{43}$

Lo que se refiere al considerar el conocimiento suficiente del derecho propio de Cataluña para la obtención de una plaza en los concursos de traslado, es una "pretensión legítima del legislador estatutario" (fundamento jurídico 51) que en todo caso será materializada o no por las Cortes Generales, que también podrán en su caso modularla. ${ }^{44}$

Conviene hacer una breve mención al tema de las lenguas que se está tratando en este precepto, y es que el cumplimiento del derecho de opción lingüística que tienen los ciudadanos de dirigirse a una institución, no tiene solamente una vía posible, es decir, que un juez o magistrado conozca la lengua no es la única forma existente de dar cumplimiento a dicho derecho. La opción más factible y admisible sin presentar mayor problema, sería recurrir a un traductor.

Por lo que se refiere al artículo 103, su redacción es la siguiente:

Artículo 103 Medios personales

\footnotetext{
42 Con este mismo criterio se expresa en el fundamento jurídico 21 relativo a la impugnación del artículo 33.3 del Estatuto que trata la acreditación por parte de jueces y magistrados de un conocimiento adecuado y suficiente de las lenguas oficiales que los hace aptos para el ejercicio de su cargo.

${ }^{43}$ Esto incluye el Derecho Internacional debidamente incorporado, el derecho interno de origen y alcance infraestatal (bien emanados de las Comunidades Autónomas, bien sean Derechos civiles forales o especiales reconocidos y amparados por la CE tal y como se señala en el fundamento jurídico 51 de la STC 31/2010. (Tribunal Constitucional de España, 99 Diputados del Grupo Parlamentario Popular del Congreso (2010): 28 de junio de 2010 (Función y contenido constitucional del Estatuto de Autonomía de Cataluña - Recurso de inconstitucionalidad). Rol No 31/2010, en página electrónica del Tribunal Constitucional http://hj.tribunalconstitucional.es/HJ/es/Resolucion/Show/6670.)

44 Es necesario aclarar que uno de los magistrados, Conde Martín de Hijas, se pronuncia sobre esto en su voto particular, señalando que debería haberse declarado la inconstitucionalidad de los preceptos porque el Estatuto se excede en sus competencias, ya que es el Estado el que debe regular esto. También se muestra disconforme a salvar los preceptos porque se realice una remisión a las leyes, ya que como establece en su voto "las normas remitidas no son condición de validez de la norma de remisión, sino que la validez de ésta es condicionante de la de las normas remitidas". Del mismo modo se pronuncia en otro voto particular el magistrado Delgado Barrio, señalando que estas exigencias lingüísticas solo pueden regularse por el Estado, atendiendo a la Constitución y mediante la Ley Orgánica del Poder Judicial y por tanto debería hacerse una declaración de inconstitucionalidad. Del mismo modo se pronuncia Rodríguez Arribas en su voto particular.
} 
1. Corresponde a la Generalitat la competencia normativa sobre el personal no judicial al servicio de la Administración de Justicia, dentro del respeto al estatuto jurídico de ese personal establecido por la Ley Orgánica del Poder Judicial. En dichos términos, esta competencia de la Generalitat incluye la regulación de:

a) La organización de este personal en cuerpos y escalas.

b) El proceso de selección.

c) La promoción interna, la formación inicial y la formación continuada.

d) La provisión de destinos y ascensos.

e) Las situaciones administrativas.

f) El régimen de retribuciones.

g) La jornada laboral y el horario de trabajo.

b) La ordenación de la actividad profesional y las funciones.

i) Las licencias, los permisos, las vacaciones y las incompatibilidades.

j) El registro de personal.

k) El régimen disciplinario.

2. En los mismos términos del apartado 1, corresponde a la Generalitat la competencia ejecutiva y de gestión en materia de personal no judicial al servicio de la Administración de Justicia. Esta competencia incluye:

a) Aprobar la oferta de ocupación pública.

b) Convocar y resolver todos los procesos de selección, y la adscripción a los puestos de trabajo.

c) Nombrar a los funcionarios que superen los procesos selectivos.

d) Impartir la formación, previa y continuada.

e) Elaborar las relaciones de puestos de trabajo.

f) Convocary resolver todos los procesos de provisión de puestos de trabajo.

g) Convocar y resolver todos los procesos de promoción interna.

b) Gestionar el Registro de Personal, coordinado con el estatal.

i) Efectuar toda la gestión de este personal, en aplicación de su régimen estatutario y retributivo.

j) Ejercer la potestad disciplinaria e imponer las sanciones que procedan, incluida la separación del servicio.

k) Ejercer todas las demás funciones que sean necesarias para garantizar una gestión eficazy eficiente de los recursos humanos al servicio de la Administración de Justicia.

3. Dentro del marco dispuesto por la Ley Orgánica del Poder Judicial, por ley del Parlamento pueden crearse cuerpos de funcionarios al servicio de la Administración de Justicia, que dependen de la función pública de la Generalitat. 4. La Generalitat dispone de competencia exclusiva sobre el personal laboral al servicio de la Administración de Justicia.

En este caso, el Tribunal, en su fundamento jurídico 52, vuelve a utilizar su técnica predilecta en el caso del Estatuto catalán, la interpretación conforme, y con ella establece que en el apartado primero de este artículo 103, la competencia normativa de la que se habla es la reglamentaria y no la legislativa, porque esta 
Villanueva - La regulación de la justicia ...

competencia legislativa se desarrolla en exclusiva por medio de la Ley Orgánica del Poder Judicial.

Por su parte, en el apartado segundo, que se refiere a la competencia ejecutiva y de gestión en materia de personal no judicial, debe ejercerse dentro del "respeto al estatus jurídico de ese personal establecido en la Ley Orgánica del Poder Judicial" (fundamento jurídico 52).

En lo que se refiere al apartado tercero, esta creación de cuerpos de funcionarios al servicio de la Administración de Justicia solo será posible si tal creación está permitida en la Ley Orgánica del Poder Judicial, y en ese caso se hará según los términos que en ella se establezcan.

Finalmente, en lo que se refiere al último apartado de este artículo 103, esta competencia exclusiva sobre el personal laboral al servicio de la Administración de Justicia, debe interpretarse en el sentido de que esta competencia no puede afectar a las competencias del Estado sobre la Administración de Justicia y de la legislación laboral general (artículos 149.1.5 y 149.1.7 CE respectivamente). ${ }^{45}$

En esta ocasión podemos ver como el Tribunal Constitucional establece una solución aceptable. No hay duda de que nos encontramos en un terreno poco firme, donde entra con más intensidad el determinar si se trata de la Administración de la Administración de Justicia o no, que como ya se adelantó en su momento, se trata de una competencia que está en manos de las Comunidades Autónomas. En mi opinión es acertado lo que han señalado Ignacio Álvarez Rodríguez e Ignacio Torres Muro cuando afirman que "las soluciones que aporta el Tribunal en este fundamento jurídico 52 parecen bastante equilibradas, puesto que, sin negar el protagonismo en estas materias de la Comunidad Autónoma catalana, lo encuadra dentro de un marco legislativo estatal, que puede contribuir a apoyar esas cautelas que también conviene reconocer". ${ }^{46}$

En lo que se refiere al artículo 104, este dice:

Artículo 104 Medios materiales

Corresponden a la Generalitat los medios materiales de la Administración de Justicia en Cataluña. Esta competencia incluye en todo caso:

a) La construcción y la reforma de los edificios judiciales y de la fiscalía.

b) La provisión de bienes muebles y materiales para las dependencias judiciales y de la fiscalia.

\footnotetext{
45 Respecto de este artículo, el magistrado Conde Martín de Hijas, señala en su voto particular que se invade la competencia que la Constitución da a la Ley Orgánica del Poder Judicial y por tanto debería declararse inconstitucional.

46 Álvarez RoDríguEZ y TORRES Muro (2011), p. 371.
} 
c) La configuración, la implantación y el mantenimiento de sistemas informáticos y de comunicación, sin perjuicio de las competencias de coordinación y homologación que corresponden al Estado para garantizar la compatibilidad del sistema.

d) La gestión y la custodia de los archivos, de las piezas de convicción y de los efectos intervenidos, en todo aquello que no tenga naturaleza jurisdiccional.

e) La participación en la gestión de las cuentas de depósitos y consignaciones judiciales y en sus rendimientos, teniendo en cuenta el volumen de la actividad judicial desarrollada en la Comunidad Autónoma y el coste efectivo de los servicios.

f) La gestión, la liquidación y la recaudación de las tasas judiciales que establezca la Generalitat en el ámbito de sus competencias sobre Administración de Justicia.

Respecto de este artículo 104, simplemente cabe señalar que no ha sido objeto de impugnación en ninguno de los distintos recursos que se han planteado acerca del Estatuto de Autonomía de Cataluña. La razón de esto resulta sencilla, y es que al leer dicho precepto, puede observarse que no hay nada que impida esta redacción, por lo que es perfectamente acorde a la Constitución.

El siguiente artículo es el 105, que establece:

Articulo 105 Oficina judicial e instituciones y servicios de apoyo

Corresponde a la Generalitat, de acuerdo con la Ley Orgánica del Poder Judicial, determinar la creación, el diseño, la organización, la dotación y la gestión de las oficinas judiciales $y$ de los órganos y servicios de apoyo a los órganos jurisdiccionales, incluyendo la regulación de las instituciones, los institutos y los servicios de medicina forense y de toxicología.

En este caso, el Tribunal señala que la Generalitat podrá intervenir en la dotación y gestión de las oficinas judiciales y de los órganos y servicios de apoyo a órganos jurisdiccionales siempre de acuerdo con lo que establezca la Ley Orgánica del Poder Judicial en este tema. ${ }^{47}$

Por su parte el artículo 106 se centra en la justicia gratuita y los procedimientos de mediación y conciliación, que tan en auge están en la actualidad. El precepto dice:

Articulo 106 Justicia gratuita. Procedimientos de mediación y conciliación

1. Corresponde a la Generalitat la competencia para ordenar los servicios de justicia gratuita y de orientación juridica gratuita.

\footnotetext{
47 En este caso, el magistrado Conde Martín de Hijas, vuelve a establecer en su voto particular que en este precepto 105, se invaden competencias reservadas a la Ley Orgánica del Poder Judicial, cosa que no discutirá respecto del artículo siguiente, respecto del cual, señala que comparte la opinión del Tribunal.
} 
Villanueva - La regulación de la justicia ...

\section{La Generalitat puede establecer los instrumentos y procedimientos de mediación y conciliación en la resolución de conflictos en las materias de su competencia.}

La regulación de la materia de asistencia jurídica gratuita se considera incluida dentro de las competencias exclusivas del Estado, no obstante, el Tribunal considera que aquí no se está regulando el derecho a la asistencia jurídica gratuita, ya que solamente se habla de ordenar los servicios relativos a esta justicia y de orientación.

Hay que tener en cuenta que tanto en el artículo 105 como en el 106, se utiliza la técnica de la interpretación conforme. Lo que se intenta hacer es salvar la competencia de la Comunidad Autónoma de Cataluña en estos terrenos que son considerados adyacentes al Poder Judicial, pero siempre manteniendo un respeto de lo que se confiere como competencia exclusiva al Estado por la Carta Magna, y también respetando lo que se establezca en la Ley Orgánica del Poder Judicial.

El artículo 107 habla de la organización del Poder Judicial, y es sin duda uno de los preceptos más polémicos dentro de este Capítulo III. Este precepto señala:

Artículo 107 Demarcación, planta y capitalidad judiciales

1. El Gobierno de la Generalitat, al menos cada cinco años, previo informe del Consejo de Justicia de Cataluna, debe proponer al Gobierno del Estado la determinación y la revisión de la demarcación y la planta judiciales en Cataluña. Esta propuesta, que es preceptiva, deberá acompañar al proyecto de ley que el Gobierno envie a las Cortes Generales.

2. Las modificaciones de la planta judicial que no comporten reforma legislativa podrán corresponder al Gobierno de la Generalitat. Asimismo, la Generalitat podrá crear Secciones y Juzgados, por delegación del Gobierno del Estado, en los términos previstos por la Ley Orgánica del Poder Judicial.

3. La capitalidad de las demarcaciones judiciales es fijada por una ley del Parlamento.

Este precepto es interpretado por el Tribunal Constitucional en el fundamento jurídico 55, aunque lo que hace el Tribunal es recalcar lo establecido en el artículo para que no haya lugar a confusión, de tal forma que sobre la proposición por parte del Gobierno de la Generalitat al Gobierno del Estado al que se hace mención en el apartado primero, señala el Tribunal que "en nada queda así perjudicada la libertad del Estado en punto al ejercicio de esa competencia", por lo que el informe por parte de la Generalitat será siempre y en todo caso, una mera propuesta. No obstante aquí sorprende que no se anule la parte relativa al previo informe del Consejo de Justicia de Cataluña, ya que este órgano fue declarado inconstitucional, por lo que si no existe el órgano, no es posible que emita ningún informe. En lo que se refiere al apartado segundo, solo recalca el Alto Tribunal que será posible siempre con plena conformidad a las leyes estatales, a lo cual ya se hace referencia en el precepto al hablar de la Ley 
Orgánica del Poder Judicial. Finalmente en cuanto a los apartados tercero y último de este artículo, son la parte del mismo más abstracta, ya que simplemente le dedica una frase que deja pie a muchas interpretaciones, de entre las cuales, el Tribunal establece que esto solo podrá ejercerse de conformidad con la Ley Orgánica del Poder Judicial, y siempre haciendo referencia a las demarcaciones judiciales que sean inferiores a la provincia. ${ }^{48}$

Si bien es cierto lo mejor hubiese sido hacer una declaración de inconstitucionalidad, en este caso el Tribunal establece de forma clara una serie de límites, atendiendo a los cuales, el artículo deja de ser una "amenaza" para la unidad del Poder Judicial.

El penúltimo de los artículos establece:

Articulo 108 Justicia de pazy de proximidad
1. La Generalitat tiene competencia sobre la justicia de paz, en los términos que
establezca la Ley Orgánica del Poder Judicial. En estos mismos términos
corresponde al Consejo de Justicia de Cataluña el nombramiento de los Jueces. La
Generalitat también se hace cargo de sus indemnizaciones y es la competente para
la provisión de los medios necesarios para el ejercicio de sus funciones. Le
corresponde también la creación de las secretarías y su provisión.
2. La Generalitat en las poblaciones que se determine y de acuerdo con lo
establecido por la Ley Orgánica del Poder Judicial, podrá instar el establecimiento
de un sistema de justicia de proximidad que tenga por objetivo resolver conflictos
menores con celeridady eficacia.

Este precepto no fue uno de los recurridos en el recurso interpuesto por el Partido Popular, y no hay pronunciamiento expreso del mismo en la STC $31 / 2010,{ }^{49}$ pero nos encontramos con que sí que es uno de los preceptos impugnados en el recurso presentado por el Defensor del Pueblo, y por tanto la STC $137 / 2010^{50}$ se pronuncia sobre él..$^{51}$ La respuesta obtenida por el Tribunal es, como no cabía

\footnotetext{
48 Como se ha hecho habitual a lo largo de esta parte de la sentencia, debe nombrarse la referencia de este artículo en el voto particular de Conde Martín de Hijas, quien considera que el precepto debe ser declarado inconstitucional.

49 Tribunal Constitucional de España, 99 Diputados del Grupo Parlamentario Popular del Congreso (2010): 28 de junio de 2010 (Función y contenido constitucional del Estatuto de Autonomía de Cataluña - Recurso de inconstitucionalidad). Rol No 31/2010, en página electrónica del Tribunal Constitucional http://hj.tribunalconstitucional.es/HJ/es/Resolucion/Show/6670.

50 Tribunal Constitucional de España, Defensor del Pueblo (2010): 16 de diciembre de 2010 (Preceptos varios del Estatuto de Autonomía de Cataluña - Recurso de inconstitucionalidad). Rol $\mathrm{N}^{\circ} 137 / 2010$ en página electrónica del Tribunal Constitucional http://hj.tribunalconstitucional.es/HJ/es/Resolucion/Show/6776.

51 Aunque la STC 137/2010 (Tribunal Constitucional de España, Defensor del Pueblo (2010): 16 de diciembre de 2010 (Preceptos varios del Estatuto de Autonomía de Cataluña - Recurso de inconstitucionalidad). Rol $\mathrm{N}^{\circ} 137 / 2010$ en página electrónica del Tribunal Constitucional http://hj.tribunalconstitucional.es/HJ/es/Resolucion/Show/6776) no es objeto de este trabajo, se ha optado por incluir el pronunciamiento sobre este artículo del Estatuto de Autonomía de
} 
Villanueva - La regulación de la justicia ...

esperar otra cosa, una interpretación conforme. Concretamente dice el Tribunal Constitucional que esta inclusión que hace el Estatuto de Autonomía de Cataluña de la Justicia de Paz como una competencia de la Generalitat, hay que entenderlo de tal modo que el Estado conserva todas sus competencias, con independencia de esta inclusión en un Estatuto de Autonomía, de tal forma que el Estatuto no va a poder limitar o condicionar al legislador estatal.

Finalmente y como cierre al bloque que se ha analizado dentro de este trabajo, nos encontramos con el último de los artículos, el cual pone punto final tanto al Capítulo III como al Título en el que se encuadra. Respecto de este precepto simplemente señalar que no ha sido recurrido ante el Tribunal, lo cual puede deberse, a la jurisprudencia del Tribunal Constitucional que permite el establecimiento de cláusulas subrogatorias.

\section{Artículo 109 Cláusula subrogatoria}

La Generalitat ejerce, además de las competencias expresamente atribuidas por el presente Estatuto, todas las funciones y facultades que la Ley Orgánica del Poder Judicial reconoce al Gobierno del Estado con relación a la Administración de Justicia en Cataluña.

Si bien es cierto que llegados a este punto se han analizado todos los preceptos que se encuentran en este Título III relativo al Poder Judicial en Cataluña, no se puede finalizar este trabajo sin hacer referencia a un precepto alejado de este Título pero referido al mismo ámbito. Se trata del artículo 180 del Estatuto, el cual dice:

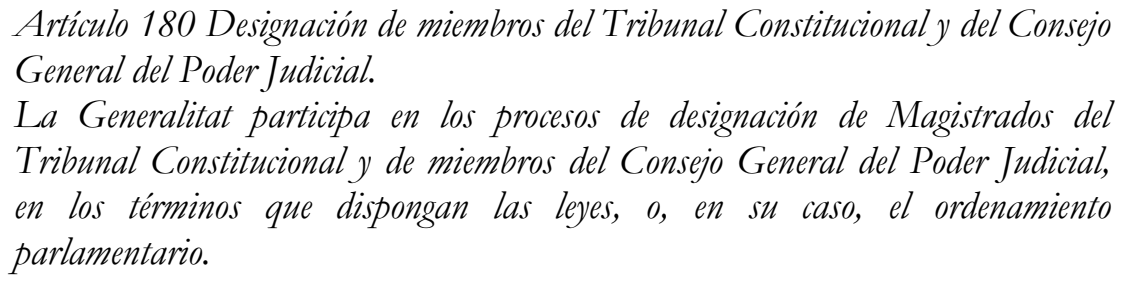

Este artículo se encuentra en la Sección Segunda del Capítulo I del Título V del Estatuto de Autonomía de Cataluña. El Tribunal Constitucional se refiere a dicho artículo en su fundamento jurídico 113, y como no podía ser de otra forma, mantiene vigente el precepto señalando que el mismo no afecta a la libertad del legislador estatal de hacerlo efectivo o no, y tampoco interfiere en la competencia del Estado para, llegado el caso, articular dicha participación. Por ello, el Alto

Cataluña dado por el Tribunal Constitucional en esta sentencia. El motivo de esta inclusión es la continuidad del método de la interpretación conforme por parte del Tribunal en la misma línea que la STC 31/2010. (Tribunal Constitucional de España, 99 Diputados del Grupo Parlamentario Popular del Congreso (2010): 28 de junio de 2010 (Función y contenido constitucional del Estatuto de Autonomía de Cataluña - Recurso de inconstitucionalidad). Rol No 31/2010, en página electrónica del Tribunal Constitucional http://hj.tribunalconstitucional.es/HJ/es/Resolucion/Show/6670. ) 
Tribunal admite que el precepto es conforme a la Constitución siempre atendiendo a lo establecido en la legislación estatal competente. ${ }^{52}$

En este caso el Tribunal vuelve a realizar una interpretación que deja desactivado el precepto interpretado, lo cual, en mi humilde opinión, resulta inconcebible. Es algo evidente que un Estatuto de Autonomía no va a poder regular ni imponer una regulación específica en esta materia, ya que se trata, sin ningún tipo de dudas, de una competencia exclusiva del Estado. En caso de que el Estado decidiera dar pie a las Comunidades Autónomas para que participasen en esta designación, esto ya estaría establecido en la propia legislación estatal, por lo que el precepto estatutario es y sería, dado el caso, superfluo.

\section{Conclusiones}

Como punto último de este estudio, y a modo de recapitulación de todo lo que en él se ha abordado, podemos señalar una serie de conclusiones básicas:

1) En primer lugar, que con la STC $31 / 2010,{ }^{53}$ se degrada el rango normativo del Estatuto de Autonomía, situándolo simplemente como una ley orgánica, que lo es formalmente, pero no debemos olvidar que tiene indudables peculiaridades materiales. Esto se contrapone a aquel sector doctrinal que considera que los Estatutos se sitúan al mismo nivel de la Constitución, y que por tanto no podían ser tachados de inconstitucionales, y también a aquel que consideraba que a la hora de analizar la constitucionalidad o inconstitucionalidad del Estatuto, se tenía que tener cierta deferencia respecto de otras normas jurídicas por estar aprobado en referéndum. Por lo tanto, con esta primera y más importante sentencia relativa al Estatuto de Autonomía de Cataluña, se rompe la teoría de la existencia del bloque de la constitucionalidad en los mismos términos que su homólogo francés.

2) En las sentencias que enjuician el Estatuto de Autonomía de Cataluña en general y en la $31 / 2010^{54}$ en particular, se puede observar una influencia política en el proceder del Tribunal Constitucional. Si bien es cierto que

\footnotetext{
52 A este respecto, los tres magistrados que han formulado votos particulares y a los que ya se ha hecho mención a lo largo de este estudio, necesitan volver a ser nombrados, puesto que tanto Conde Martín de Hijas como Delgado Barrio y Rodríguez Arribas, señalan que el precepto está redactado de forma que no da lugar a confusión posible, y por ello consideran que debería haber sido declarado inconstitucional sin ningún tipo de duda.

53 Tribunal Constitucional de España, 99 Diputados del Grupo Parlamentario Popular del Congreso (2010): 28 de junio de 2010 (Función y contenido constitucional del Estatuto de Autonomía de Cataluña - Recurso de inconstitucionalidad). Rol No 31/2010, en página electrónica del Tribunal Constitucional http://hj.tribunalconstitucional.es/HJ/es/Resolucion/Show/6670.

54 Tribunal Constitucional de España, 99 Diputados del Grupo Parlamentario Popular del Congreso (2010): 28 de junio de 2010 (Función y contenido constitucional del Estatuto de Autonomía de Cataluña - Recurso de inconstitucionalidad). Rol No 31/2010, en página electrónica del Tribunal Constitucional http://hj.tribunalconstitucional.es/HJ/es/Resolucion/Show/6670.
} 
esta influencia no es explícita, lo cual supondría una desacreditación absoluta del órgano, esta si se manifiesta en la presión pública hacia el Tribunal, las recusaciones planteadas y la imposibilidad de aceptar a un ponente hasta que la presidenta decide situarse en dicha posición, dando lugar a una sentencia que no desacredita al tribunal de forma absoluta pero si provoca una merma en cuanto al prestigio que se había ganado a lo largo de estos años de funcionamiento.

3) La sentencia $31 / 2010^{55}$ resultante del examen realizado por el Tribunal, no es ni mucho menos la que cabría esperar, puesto que en vez de obtener una sentencia declarando la inconstitucionalidad o constitucionalidad del Estatuto impugnado, nos encontramos con una sentencia interpretativa en su gran mayoría y que de forma subsidiaria decide optar por la declaración de inconstitucionalidad para determinados preceptos a los que es imposible salvar con otra técnica. No obstante, con la sentencia en la mano, puede afirmarse que el Estatuto de Autonomía de Cataluña en general y el Título III, en particular, tal y como se ha concebido ha sido desactivado.

4) Al hablar de sentencia interpretativa, es necesario hacer mención a la incorrecta utilización de la técnica de la interpretación conforme. El Tribunal Constitucional no hace otra cosa que darle la vuelta al sentido literal de un número importante de artículos, algo que contradice claramente el espíritu que encierra esta técnica, la cual debe usarse cuando existe al menos una interpretación que es acorde con la Constitución, y no cabe su utilización cuando la única interpretación posible es la inconstitucional.

5) Adentrándonos en lo que sería el Título III, resulta cuanto menos destacable que se regule el Poder Judicial en un Estatuto de Autonomía, cuando es, a todas luces, una norma incompetente para establecer una regulación sobre el mismo, con independencia de que esta regulación sea conforme o no a la legislación estatal vigente, y con independencia de que se hagan referencias a la ley estatal encargada de regular dicho Poder. Aún en el caso de que tener presente que, en atención a la jurisprudencia constitucional las Comunidades Autónomas tienen competencia en Administración de la Administración de Justicia, ello no puede equivaler a dedicarle un capítulo entero al Poder Judicial. Únicamente sería admisible el establecimiento de preceptos estatutarios relativos a esa pequeña parcela de actuación que el Alto Tribunal ha otorgado a las Comunidades Autónomas.

6) Asimismo resulta criticable, cuanto menos, el intento de salvar el órgano del Consejo de Justicia, que si bien es cierto que es un órgano anulado por el Tribunal, este intenta dejar una puerta abierta al mismo permitiendo que parte de sus competencias y su composición sigan vigentes, cuando es evidente que si no

\footnotetext{
55 Tribunal Constitucional de España, 99 Diputados del Grupo Parlamentario Popular del Congreso (2010): 28 de junio de 2010 (Función y contenido constitucional del Estatuto de Autonomía de Cataluña - Recurso de inconstitucionalidad). Rol No 31/2010, en página electrónica del Tribunal Constitucional http://hj.tribunalconstitucional.es/HJ/es/Resolucion/Show/6670.
} 
existe órgano, no pueden existir las otras dos cosas. Lo que hace el Tribunal, no es otra cosa que un juicio preventivo de constitucionalidad.

Una vez realizada esta breve recapitulación de los aspectos más destacables de todo lo que se ha tratado en este estudio, debe decirse que tras las sentencias del Tribunal Constitucional sobre el Estatuto de Autonomía de Cataluña, especialmente la STC 31/2010, ${ }^{56}$ el Poder Judicial en la Comunidad Autónoma no va a ser lo que se pretendía en el texto estatutario. El Tribunal Constitucional ha realizado una profunda revisión de este Título, intentando mantener un cierto respeto hacia el legislador orgánico estatutario, que se manifiesta no solo en los poco artículos declarados inconstitucionales, sino en el empeño del Alto Tribunal de salvar todos aquellos preceptos que le era posible. Pese a las críticas, tanto positivas como negativas, que han tenido todos estos pronunciamientos del Tribunal Constitucional en general y más en concreto la sentencia $31 / 2010^{57}$ en particular, queda latente la idea de que el Tribunal Constitucional desaprovecha una oportunidad de oro, en la que podía haber fijado de forma clara los límites constitucionales al sistema autonómico y dotarlo de racionalidad, actualizando el sistema que la Constitución Española de 1978 instauró en su momento para dar respuesta a una difícil situación que estaba teniendo lugar intentando contentar a todos los territorios, especialmente en los que se presentaban más conflictos. Lejos de realizar esta delimitación de nuestro sistema territorial, uno de los más descentralizados en la actualidad, lo que hace es dejarlo entreabierto, algo que dudosamente puede dar un nivel de seguridad y estabilidad adecuados al orden autonómico establecido en el Estado español.

\footnotetext{
56 Tribunal Constitucional de España, 99 Diputados del Grupo Parlamentario Popular del Congreso (2010): 28 de junio de 2010 (Función y contenido constitucional del Estatuto de Autonomía de Cataluña - Recurso de inconstitucionalidad). Rol No 31/2010, en página electrónica del Tribunal Constitucional http://hj.tribunalconstitucional.es/HJ/es/Resolucion/Show/6670.

57 Tribunal Constitucional de España, 99 Diputados del Grupo Parlamentario Popular del Congreso (2010): 28 de junio de 2010 (Función y contenido constitucional del Estatuto de Autonomía de Cataluña - Recurso de inconstitucionalidad). Rol No 31/2010, en página electrónica del Tribunal Constitucional http://hj.tribunalconstitucional.es/HJ/es/Resolucion/Show/6670.
} 
Villanueva - La regulación de la justicia ...

\section{BIBLIOGRAFÍA}

* Albertí Rovira, Enoch (2010): "La Sentencia 31/2010: Valoración general de su impacto sobre el Estatuto y el Estado de las Autonomías", Revista catalana de dret públic: Especial Sentencia sobre el Estatuto, ( $\mathrm{N}^{\circ}$ Extra 1) pp. 11 - 22. Disponible en: http://revistes.eapc.gencat.cat/index.php/rcdp/article/viewFile/144/154. Última consulta realizada el 19/05/2014.

* Álvarez Rodríguez, Ignacio y Torres Muro, Ignacio (2011): "El Poder Judicial en Cataluña en la STC 31/2010, de 28 de junio", Teoría y realidad Constitucional, (N $\left.{ }^{\circ} 27\right)$. pp. 345 375.

* Aparicio PÉrez, Miguel Ángel (2010): “Comentario a la Sentencia 31/2010. Sobre el Poder Judicial”, Revista catalana de dret públic: Especial Sentencia sobre el Estatuto, (No Extra 1). pp. 199 205. Disponible en: http://revistes.eapc.gencat.cat/index.php/rcdp/article/viewFile/153/172. Última consulta realizada el 19/05/2014.

* Blanco Valdés, Roberto Luís (2010): "El Estatuto Catalán y la Sentencia de nunca acabar", Claves de razón práctica, $\left(\mathrm{N}^{\circ}\right.$ 205). pp. 4 - 18.

* Cabellos EspiÉrrez, Miguel Ángel (2010): "Poder Judicial y modelo de Estado en la Sentencia sobre el Estatuto de Autonomía de Cataluña", Revista catalana de dret públic: Especial Sentencia sobre el Estatuto, ( ${ }^{\circ}$ Extra 1). pp. 206 - 211. Disponible en: http://www10gencat.net/eapc_revistadret//recursos_intereses/especial\%20estatut/documen ts\%20especial\%20estatut/cast/09_Cabellos_es.pdf. Última consulta realizada el 17/05/2014.

* Caldera Infante, Jesús Enrique (2012): "El Bloque de Constitucionalidad como herramienta de protección de los derechos fundamentales. Una aproximación al estudio de sus aportes desde el derecho procesal constitucional", Tercer congreso colombiano de derecho procesal constitucional y segundo encuentro de la asociación mundial de justicia constitucional: Asociación colombiana de derecho procesal constitucional, Cali. Disponible en: http://nuevagobernanza.com.co/documentos/13.pdf. Última consulta realizada el 09/06/2014.

* Ferrelles Comella, Víctor (2010): "El Tribunal Constitucional ante el Estatuto", Revista Catalana de dret públic, Especial sentencia sobre el Estatuto, ( $\mathrm{N}^{\circ}$ Extra 1). pp. $74-78$.

* Flórez Turrado, Francisco Javier (2012): ¿Hacia un Estado Autonómico Desconstitucionalizado?: El fututo del modelo territorial español en el marco de la integración europea (Oñati, IVAP). 335 pp.

* García de EnTERría, Eduardo (1981): La Constitución como norma y el Tribunal Constitucional (Madrid, Civitas). 332 pp.

* Hoyos, Arturo (1992): "El control judicial y el Bloque de la Constitucionalidad en Panamá", Boletín Mexicano de Derecho Comparado. pp. $95-117$.

* Rubio Llorente, Francisco (1989): "El Bloque de Constitucionalidad", Revista Española de Derecho Constitucional, (No 27). pp. 9 - 38.

* Tur Ausina, Rosario y Álvarez Conde, Enrique (2010): Las Consecuencias Jurídicas de la Sentencia 31/2010, de 28 de junio del Tribunal Constitucional sobre el Estatuto de Cataluña. La Sentencia de la Perfecta Libertad (Navarra, Aranzadi). 352 pp.

* Villanueva Turnes, Alejandro (2014): "En atención ao Bloque da Constitucionalidade", Cadernos de Dereito Actual, (No 2). pp. 59 - 70.

* VV.AA. (2014): Enciclopedia Jurídica (Chipre, Constantinos Stamatoulos).

\section{Normas Jurídicas citadas:}

* Constitución Española de 1978.

* Ley Orgánica 2/1979, de 3 de octubre, del Tribunal Constitucional.

* Ley Orgánica de Armonización del Proceso Autonómico, de 30 de julio de 1982.

* Ley Orgánica 6/1985, de 1 de julio, del Poder Judicial. 
Ley Orgánica 6/2006, de 19 de julio, de reforma del Estatuto de Autonomía de Cataluña.

\section{Referencias Jurisprudenciales:}

* Tribunal Constitucional de España, Gobierno Vasco, por el Parlamento Vasco, por el Consejo Ejecutivo de la Generalidad de Cataluña, por el Parlamento de Cataluña y por 50 Diputados de las Cortes Generales (1983): 5 de agosto de 1983 (Proyecto de Ley Orgánica Armonizadora del Proceso autonómico - Recurso de inconstitucionalidad). Rol N $\mathrm{N}^{\mathrm{o}} 76 / 1983$ en página electrónica del Tribunal Constitucional http://hj.tribunalconstitucional.es/HJ/es/Resolucion/Show/204.

* Corte Suprema de los Estados Unidos, Romers vs Evans (1996): 20 de mayo de 1996 (Derechos parejas homosexuales). Rol No 517 US 620 en página de la Corte de justicia https://supreme.justia.com/cases/federal/us/517/620/case.html

* Tribunal Constitucional de España, 99 Diputados del Grupo Parlamentario Popular del Congreso (2010a): 28 de junio de 2010 (Función y contenido constitucional del Estatuto de Autonomía de Cataluña - Recurso de inconstitucionalidad). Rol No 31/2010 en página electrónica del Tribunal Constitucional http://hj.tribunalconstitucional.es/HJ/es/Resolucion/Show/6670.

* Tribunal Constitucional de España, Defensor del Pueblo (2010b): 16 de diciembre de 2010 (Preceptos varios del Estatuto de Autonomía de Cataluña - Recurso de inconstitucionalidad). Rol N $N^{\circ} 137 / 2010$ en página electrónica del Tribunal Constitucional http://hj.tribunalconstitucional.es/HJ/es/Resolucion/Show/6776. 